\title{
Factores de riesgo y complicaciones de la infección de vías urinarias durante el embarazo
}

\author{
Dres.: Jacinto Sánchez Angarita*, Antonio Lomanto Morán**
}

\begin{abstract}
RESUMEN: Las infecciones de vías urinarias (UTI) representa un grupo de enfermedades que constituyen las complicaciones médicas más frecuentes del embarazo. Abarcan desde la bacteriuria asintomática hasta la pielonefritis, y puede producir morbilidad y mortalidad notoria.

La gravedad potencial de la pielonefritis y sus complicaciones requieren hospitalización y tratamiento parenteral. No obstante, tienen importancia semejante los sistemas de prevención de infecciones iniciales y recidivantes.

La pielonefritis es una infección grave del embarazo y es consecuencia de bacteriuria no detectada. Cuando se confirma pielonefritis es indispensable el tratamiento inmediato, con la esperanza de prevenir las secuelas maternas fetales potencialmente graves. Después de un tratamiento eficaz, se requiere vigilancia y supresión cuidadosa durante el resto del embarazo. Sin embargo, debido a la gran incidencia de recidivas, está garantizado hacer urocultivos y estudios radiográficos postparto y en embarazo subsiguientes, en un intento por descubrir anomalías renales subyacentes.

El choque séptico subsecuente a una pielonefritis durante el embarazo debe identificarse tempranamente y tratarse en forma intensiva. El tratamiento exitoso debe dirigirse a la estabilización del estado de la paciente, eliminación de la causa de la septicemia, cobertura con antibióticos de amplio espectro y tratamiento de complicaciones concomitantes.
\end{abstract}

PALABRAS CLAVES: Infección Urinaria, embarazo.

SUMMARY: The Urinary Infection (UTI) represent a high proportion of diseases that account for the complications during pregnancy in medical practice.

The spectrum of this complications might change from asimtomatic Bacteriuria, Through Pielonefrinitis, and could result in high morbility and mortality. The potencial severity of the pielonetritis and the complications of this disease usualy needs hospitalization with parenteral treatment, making so important prevent this infections with very acquard measures.

The pielonefritis is a very seriovs infection, during the pregnancy and is the result of an no detected Bacteriuria. When the pielonefritis has been confirm the treatment must be quinckly; with the hope of prevent a long term complication in the mother as well as in the child.

After a succes'full treatment it's necessary to check the mother during the rest of the pregnancy with urocultives and radiographic studies as well as in future pregnancies. Because the high proportion of the renal anormalities.

The Shock septic after an episode of pielonefritis during the pregnancy, must be identifes soon and have a very drastic treat ment that involve elimination of the cause and aplication of antibiotic of high spectrum.

KEY WORDS: Urinary Infectión, Pregnancy.

Las infecciones de las vías urinarias, que incluyen la bacteriuria asintomática (ASB), la cistitis y la pielonefritis, son comunes en embarazadas y no embarazadas. Aunque la gestación en sí no incrementa la prevalencia global de estas infecciones en mujeres, hay cambios y aumenta la incidencia de la infección sintomática aguda, en particular la pielonefritis aguda. Esta última entidad es rara en la no embarazada en tanto que en el embarazo, se transforma en el trastorno médico más común, por lo cual se hospitaliza a la paciente, Además, las infecciones agudas de vías urinarias constituyen una fuente de complicaciones serias para la embarazada y el feto. En su forma más grave, la pielonefritis aguda y la endotoxemia resultante pueden ocasionar

\footnotetext{
* Profesor asistente del Depto. de Ginecología y Obstetricia. Facultad de Medicina, Universidad Nacional de Colombia.

** Profesor asociado, Depto. Ginecología y Obstetricia. Facultad de Medicina, Universidad Nacional de Colombia.
}

insuficiencia de múltiples órganos y sistemas de la gestante, con deterioro concomitante de la unidad uteroplacentaria.

\section{Factores predisponentes de la infección uri-} naria

La razón por la que existe mayor incidencia de infección urinaria durante el embarazo no está totalmente aclarada, aunque se supone que debe existir alguna relación con las modificaciones que el embarazo produce en el tracto urinario, las que han sido consideradas con criterios controvertidos como fisiológicas.

A continuación se mencionan algunos factores que influyen en este proceso relacionados con el germen, el huésped y el comportamiento de la infección:

\section{El germen}

Una serie de observaciones ha demostrado que las mujeres con infecciones urinarias colonizan su introito vaginal 
y uretra con enterobacterias antes de iniciarse el proceso infeccioso y estarán en peligro o con tendencia a la infección mientras esta colonización no cambie a una situación normal $(1,2)$. La gran mayoría de las infecciones del tracto urinario son causadas por microorganismos de la flora microbiana normal del intestino. Aproximadamente el $80 \%$ de las infecciones adquiridas fuera del hospital y no acompañadas de obstrucción son causadas por E. coli.

Existen al menos 200 serotipos de E. coli, de los cuales 150 corresponden a serotipos relacionados con los antígenos de la pared celular o antígenos $\mathrm{O}$, alrededor de 100 corresponden a los antígenos de la cápsula o antígeno $\mathrm{K}$, y los 50 restantes a los antígenos flagelares o antígenos $\mathrm{H}$. Los factores de virulencia de E. coli y su capacidad de invadir el tracto urinario no están perfectamente aclarados $(3,4)$. Se ha sugerido que su patogenidad podría estar relacionada con la capacidad de una cepa determinada por proteínas de superficie (antígeno K) que al parecer las hace resistentes a la fagocitosis y a su destrucción por el complemento $(5,6)$.

Está demostrado que unos serotipos son más frecuentes en las infecciones urinarias, que otros tipos (tipos 1, 2, 4, $6,7,25,50,75)$ pero estos serotipos son al mismo tiempo los más frecuentes presentes en la flora fecal normal (Tabla 1).

Después de E. coli, los microorganismos del género Proteus causan frecuentemente infecciones urinarias. Los Proteus indol positivos son más virulentos y propios de ambientes hospitalarios.

También el Enterobacter y el Citrobacter se han involucrado entre los agentes etiológicos de las infecciones urinarias. Por último es conveniente mencionar el género de las Pseudomonas las cuales originan infección urinaria en pacientes con sondas y con graves enfermedades subyacentes (Tabla 2).

\section{El huésped}

2.1. Vías de infección: Entre las diversas rutas por las que las bacterias pueden alcanzar el tracto urinario, la vía ascendente, a través de los conductos naturales, que relacionan el tracto urinario con el exterior, aparece actualmente como la vía infectiva más común. Uno de los hallazgos que fundamenta ésta ha consistido en la demostración de bacterias patógenas en el introito y en la zona periuretral femenina, precediendo a la invasión bacteriana del árbol urinario.

Está bien establecido que las bacterias son, precisamente, las mismas que se encuentran en las heces. Sin embargo debe producirse una selección natural de las bacterias que participan en la infección urinaria, ya que otras, que son mucho más comunes en las heces como los bacteroides $\mathrm{Sp}$. raramente son reconocidas como agentes desencadenantes de la infección urinaria. En este sentido, es muy significativo el hallazgo de E. coli, que es el responsable de la mayoría de las infecciones urinarias extrahospitalarias, y sólo repre-

Tabla 1

SEROTIPOS DE E. COLI AISLADOS

DE LAS INFECCIONES URINARIAS

\begin{tabular}{|llllllllll|}
\hline Serotipo & 01 & 04 & 06 & 07 & 09 & 011 & 018 & 039 & 075 \\
Número & 7 & 25 & 28 & 5 & 3 & 3 & 22 & 1 & 16 \\
Porcentaje & $6.4 \%$ & $22.7 \%$ & $25.4 \%$ & $4.5 \%$ & $2.7 \%$ & $2.7 \%$ & $20 \%$ & $0.9 \%$ & $14.5 \%$ \\
\hline
\end{tabular}

Tabla 2

BACTERIOLOGIA EN LA INFECCION URINARIA

\begin{tabular}{|llccc|c|}
\hline Autor & Ref. & E.coli & Klebsiella Enterobacter Proteus Cocos G \\
(t)
\end{tabular}

senta el $1 \%$ de los organismos presentes en las heces. La descripción de las vías por las que las bacterias en las heces pueden alcanzar el árbol urinario, representa un tema clásico en el estudio de la etiopatogenia de la pielonefritis.

La vía hemática es ocasionalmente utilizada por otras bacterias, especialmente por bacterias gram positivas y concretamente por estafilococo y su acceso al riñón por esta vía justifica diversas circunstancias sépticas renales y perirrenales, entre las que se destaca el antrax renal.

En recientes investigaciones se ha podido comprobar que las bacteremias por gram negativos comprometen el riñón cuando la estructura renal está afectada, bien por trastornos anatómicos intrínsecos o a consecuencia de defíciencias urodinámicas.

En clínica la bacteremia gram negativa seguramente se produce no sólo a consecuencia de maniobras instrumentales, sino en algunos casos en individuos con estenosis del árbol urinario inferior.

Existen conexiones entre los linfáticos intestinales y el riñón, pero la participación de la vía linfática en la producción de infecciones en el árbol urinario es discutible. Se supone que las bacterias intestinales pueden escapar atravesando la pared intestinal, para ser posteriormente transportadas por vía linfática hasta el árbol urinario pero las experiencias en este sentido no han sido concluyentes.

2.2. Características de la mucosa: Un individuo puede colonizar su perineo con un uropatógeno que tiene pelos del tipo I pero no desarrolla infección. La vejiga es muy resistente a la infección; su principal defensa resulta ser el efecto constante de lavado ejercido por la orina más una superficie "no adherente". La vejiga está revestida por un glucosaminoglucano (GAG) muy eficaz para disminuir la adherencia bacteriana a la mucosa. La disminución de la cantidad o de la eficacia del GAG sugiere que también desempeña cierto papel en la cistitis recurrente. Se ha demostrado que la adherencia bacteriana a la vejiga esta disminuida si se sustituyen los GAG o análogos $(7,8,9)$.

La adherencia de bacterias a las células mucosas es un pre-requisito ampliamente aceptado para la colonización e infección de superficies mucosas, incluyendo tubo digestivo, vías respiratorias y vías genitourinarias. Es posible que la interacción de la mucosa y la célula bacteriana dependa de receptores en la mucosa y de cierto tipo de mecanismo de fijación utilizados para las bacterias. Estudios iniciales indicaron que puede haber un aumento de adherencia de E. coli a las células vaginales en mujeres con tendencia a la cistitis 
comparadas con las normales; pero estas observaciones las han puesto en duda otros autores (10). Sin embargo puede ocurrir que las células de la mucosa vaginal de hembras susceptibles proporcionen receptores bacterianos que faciliten tal adherencia. Se han identificado varios receptores.

La mucosa se considera importante para la cistitis, y el antígeno de grupo sanguíneo $\mathrm{P}$ para la pielonefritis. Las bacterias tienen tipos especiales de estructuras de superficie (de la célula microbiana) que utilizan como medio de adhesión. Estas estructuras se llaman pelos y pueden presentarse en gran número en la superficie de la célula microbiana. Se han identificado dos tipos que tienen importancia en infecciones urinarias. Los pelos de tipo I buscan mucosa como receptor, y se han aislado de individuos con cistitis. Por otra parte, los pelos A negativos o "P pili" se adhieren al grupo sanguíneo P. Es más frecuente encontrar estos antígenos en cepas bacterianas aisladas de casos de pielonefritis.

\subsection{Cambios en las vías urinarias por el emba-}

razo: La morfología de las vías urinarias se modifica marcadamente durante el embarazo la longitud renal aumenta aproximadamente $1 \mathrm{~cm}$; durante el embarazo normal. Se piensa que este fenómeno no refleja una verdadera hipertrofia sino que es el resultado de un mayor volumen vascular e instersticial en el riñón. No se han detectado alteraciones histológicas en las biopsias renales de estas mujeres. El sistema colector, especialmente los uréteres, muestran una disminución del peristaltismo durante el embarazo, y la mayoría de las mujeres en el tercer trimestre de la gestación presentan un grado significativo de dilatación ureteral. El útero aumentado de tamaño desplaza la vejiga hacia arriba y adelante, la vejiga adquiere un aspecto hiperémico con aumento de su capacidad, hipotonía y vaciamiento incompleto. El incremento de volumen de orina en el sistema urinario, la estasis y el reflujo vesicoureteral facilitan el paso de orina infectada desde la vejiga hacia las vías superiores y su proliferación (11).

$\mathrm{El}$ incremento transitorio del índice de filtración glomerular y del flujo plasmático renal durante el embarazo ha sido consignado por diversos autores y es probable que sea secundario al aumento de volumen minuto cardíaco. La filtración glomerular aumenta en un 30 a $50 \%$ y la excreción urinaria de proteínas se incrementa. La importancia de estas alteraciones fisiológicas se hace evidente cuando se estudian los valores séricos normales de creatininas y de nitrógeno ureico en las mujeres embarazadas. Los valores considerados normales en mujeres no embarazadas pueden reflejar una insuficiencia renal durante el embarazo.

2.4. Factores mecánicos: La investigación epidemiológica ha demostrado que la infección urinaria es más frecuente en aquellos individuos que tienen trastornos en el mecanismo de transporte desde la papila a la vejiga y en el vaciamiento vesical.

La obstrucción en el árbol urinario superior es considerada como la causa predisponente más importante de la infección urinaria, de tal modo que la pielonefritis se clasifica en obstructiva y no obstructiva. La obstrucción puede localizarse en diversos sitios del aparato excretor. En el sector superior son bien conocidas las obstrucciones provo- cadas por alteraciones congénitas como la hidronefrosis y el megauréter así como las obstrucciones secundarias a procesos inflamatorios y tumorales. En el árbol urinario inferior, la infección es frecuente en individuos con estenosis uretral, disfunciones neurogénicas vesicouretrales o cistocele de gran magnitud. Además de los casos mencionados, las obstrucciones y la estasis intervienen como factores patógenos en otras circunstancias en las que la infección urinaria es más frecuente, como el embarazo y la diabetes mellitus.

a. Obstrucciones y estasis: Las dilataciones del tracto urinario superior no son siempre la consecuencia de la obstrucción. La dilatación puede ser secundaria a un defecto morfológico o a una causa obstructiva que ya es inoperante en el momento en que se reconoce la dilatación. En cualquier caso y con mayor o menor gravedad, la dilatación del árbol urinario superior interfiere con el transporte de la orina desde la papila renal hasta la vejiga. En estas condiciones la peristalsis es ineficaz, ya que no se consigue la constricción de la luz ureteral. La estasis facilita la infección y sobre todo dificulta notablemente la erradicación de una infección establecida por el efecto inóculo.

b. Patología intrarrenal y nefrodinámica: La obstrucción no afecta sólo el sector superior, sino que puede localizarse a nivel intrarrenal dificultando el transporte de orina dentro de los diferentes elementos nefronales. El concepto de obstrucción intrarrenal como facilitador de la infección urinaria, y en este caso de la pielonefritis, puede ser la consecuencia de muy diversos tipos de patología renal como infartos, necrosis, nefropatías y enfermedades del colágeno.

c. Reflujo vesicorrenal: La válvula vesicoureteral en condiciones fisiológicas sólo permite el paso de la orina desde el uréter hasta la vejiga. El reflujo de orina vesical hacia el árbol urinario superior durante el llenado vesical o la micción presenta un hecho patológico de variable gravedad. El reflujo puede deberse a un defecto primario, congénito de la válvula ureterovesical o ser consecuencia de procesos adquiridos espècialmente obstructivos o inflamatorios.

Las investigaciones clínicas han podido demostrar que los enfermos que tienen reflujo vesicoureteral producen con más frecuencia que el resto de otras poblaciones equiparables de infección urinaria recidivante, hipertensión o insuficiencia renal. La lesión renal que produce el reflujo tiene unas peculiaridades estructurales que permiten identificarla de manera independiente con el nombre de "Pielonefritis de reflujo".

d. Situaciones especiales: En este grupo se ha incluido la distensión uterina excesiva, cálculos, cirugías previas y malformaciones. La frecuencia de cálculos en el embarazo varía ampliamemte según los distintos autores. Harris (12) en 1967 reporta una incidencia del $0.16 \%$ de litiasis. La pielonefritis acompañó a este cuadro en un $89 \%(17 / 19$ casos). Horowitz (13) en una revisión de casos publicados después de 1980, informa una incidencia de $0.24 \%$ y un $17 \%$ de urocultivos positivos (14/81). La cirugía previa de uréteres como la reimplantación o la derivación puede predisponer a la obstrucción y a la infección durante el embarazo (14). Barret presenta cinco embarazos en derivación ureteral con 2 casos de bacteriuria y 5 de pielonefritis; una revisión de la literatura de 47 casos de este tipo de cirugía presentaron pielonefritis en un $14.9 \%$ y obstrucción en $12.8 \%$ (15). 


\section{Complicaciones de la infección del tracto uri- nario}

\section{A. Médicas:}

Las infecciones de las vías urinarias representan un grupo de enfermedades que constituyen las complicaciones médicas más frecuentes del embarazo. Abarcan desde la bacteriuria asintomática hasta la pielonefritis, y pueden producir morbilidad y mortalidad notorias. La gravedad potencial de la pielonefritis y sus complicaciones requiere hospitalización y tratamiento parenteral. No obstante tienen importancia semejante los sistemas de prevención de infecciones iniciales y recidivantes.

Se define como bacteriuria asintomática el aislamiento del mismo microorganismo patógeno urinario en dos muestras consecutivas, con más de 100.000 unidades formadoras de colonias por $\mathrm{ml}$, recolectadas por el método de chorro medio en una paciente sin manifestaciones clínicas.

La prevalencia de la bacteriuria en niños y mujeres se inicia con una tasa de $1.2 \%$ en escolares que cursan del primer a tercer año de primaria y después aumenta a una velocidad de 1 a $2 \%$ en cada decenio de la vida. Kunnin (16) encontró una tasa de $3.5 \%$ en adolescentes de 15 a 19 años con aumento súbito al iniciar su vida sexual. Sleigh y col. encontraron una tasa del $8 \%$ en mujeres con actividad sexual que acudían a una clínica de esterilidad. Se informa de bacteriuria asintomática en 2.5 a $9.7 \%$ de las embarazadas, dependiendo del grupo específico estudiado. En el Instituto Materno Infantil de Bogotá se encontró una frecuencia del 3\% en 1987 (17) (Tabla 3). Otros factores que aumentan la incidencia de la bacteriuria son la tendencia a la anemia de células drepanocíticas, nivel socioeconómico bajo y una mayor paridad

Aunque la incidencia y gravedad de cistitis y pielonefritis aumentan durante el embarazo, no parece que se modifique la tasa de bacteriuria asintomática. La gran parte de diagnósticos de bacteriuria asintomática durante el embarazo se hacen en el momento de la primera consulta prenatal (18).

Se define a la cistitis como la presencia de síntomas de infección de vías urinarias bajas acompañado de cultivo positivo que se presenta de 1.3 a $3.4 \%$ de las embarazadas.

Tabla 3

PREVALENCIA DE LA BACTERIURIA ASINTOMATICA DURANTE EL EMBARAZO

\begin{tabular}{|lrrr|}
\hline Autor & $\begin{array}{r}\text { Núm. de } \\
\text { pacientes }\end{array}$ & $\begin{array}{r}\text { Núm. con } \\
\text { bacteriuria }\end{array}$ & Porcentaje \\
\hline Blunt y Williams & 1055 & 27 & 2.5 \\
Williams y col. & 5542 & 211 & 3.8 \\
Gower y col. & 5000 & 265 & 4.4 \\
Kincaid-Smith y Bullen & 4000 & 240 & 6.0 \\
Sleigh y col. & 1684 & 111 & 6.6 \\
Whalley y col. & 4357 & 303 & 7.0 \\
Bryant y col. & 448 & 32 & 7.1 \\
Monson y col. & 1400 & 102 & 7.3 \\
Patrick & 2521 & 219 & 8.7 \\
Le Blanc y McGainty & 1325 & 129 & 9.7 \\
Lomanto A. y Sánchez A. & 1000 & 30 & 3.0 \\
\hline
\end{tabular}

Estos síntomas pueden incluir imperiosidad urinaria, polaquiuria y disuria. Tradicionalmente se señala como cultivo positivo aquel con más de 100.000 colonias por $\mathrm{ml}$ de un uropatógeno en una muestra de chorro medio. Sin embargo Stamm y col. demostraron que cifras de apenas 100 colonias pudieran indicar infección en pacientes sintomáticas.

La pielonefritis aguda es una inflamación del parénquima renal demostrada por cultivo positivo aunado a manifestaciones de infección de vías urinarias altas, como fiebre, escalofríos, hipersensibilidad en flancos, dolor lumbar, náuseas y vómito (Tabla 4). Ocurre pielonefritis aguda en el 1 a $2 \%$ de las embarazadas, 70 a $80 \%$ en aquellas con antecedentes de bacteriuria asintomática. Si esta última no se trata, 20 a $40 \%$ de las pacientes presentan después pielonefritis aguda (19). Esta suele ocurrir en la segunda mitad del embarazo. Duff (20) encontró que sólo $2 \%$ de las pacientes con pielonefritis aguda la presentaron en el primer trimestre; $52 \%$ en el segundo y el $46 \%$ durante el tercero.

La embarazada que muestra pielonefritis suele señalar antecedentes que permiten al médico hacer el diagnóstico con facilidad. Por lo regular, los síntomas se desarrollan en forma rápida y todas las mujeres tienen fiebre en algún momento de la infección, temperatura que llega a 40 grados o mayores. La mayoría de las pacientes tienen escalofríos y dolor de costado ( $85 \%)$; muchas tienen náuseas y vómito (25\%) y un número importante tienen síntomas de porción inferior de vías urinarias (40\%). En algunas mujeres son comunes los síntomas generalizados con cefalea, fatiga, mialgias, y en otras predominan signos y síntomas de sepsis por gram negativos. Estos efectos mediados por endotoxinas afectan a muchos órganos y sistemas que incluyen: inestabilidad termorreguladora, disfunción pulmonar, trombocitopenia y anemia; hepatitis tóxica, anormalidades de la función renal y shock endotóxico (Tabla 4).

Tabla 4

\begin{tabular}{|lc|}
\hline Síntomas & $\%$ \\
Dolor de espalda y escalofríos & 82 \\
Síntomas de las vías urinarias inferiores & 40 \\
Náusea y vómito & 24 \\
\hline Signos & \\
Temperatura 38.3C & 84 \\
Temperatura 40C & 12 \\
Sensibilidad ACV derecho & 54 \\
Sensibilidad ACV bilateral & 27 \\
Sensibilidad ACV izquierdo & 16 \\
\hline
\end{tabular}

a.Inestabilidad termorreguladora: La fiebre alta en agujas con temperaturas que fluctúan rápidamente de 34 a 42 grados es un signo que a menudo surge en la pielonefritis aguda. Estas temperaturas extremas tal vez sean mediadas a nivel del hipotálamo, por algún pirógeno endógeno estimulado por las endotoxinas. La mejoría y respuesta de la fiebre al tratamiento tiene gran importancia clínica. Cunningham (21) y Hibbard (22) proponen que con tratamiento rápido la mayoría de las mujeres terminan por no mostrar fiebre en término de 48 a 72 horas de la terapéutica. Si no se logra la respuesta clínica en 72 horas o hay empeoramiento del estado de la mujer dentro de tal lapso, el clínico debe atender 
la posibilidad de que exista un microorganismo resistente, obstrucción de vías urinarias o absceso peri-renal.

b. Complicaciones renales: En la pielonefritis aguda los productos secundarios de los microorganismos patógenos, como sería la fracción de endotoxina integrada por el lipopolisacárido de la pared, se liberan en la circulación, en la que pueden viajar y producir disfunción del mismo riñón y del contrario.

Varios investigadores demostraron alteraciones de la función renal en pacientes con infecciones urinarias. Se encontró alteración de la capacidad de concentración urinaria en casi $45 \%$ de las pacientes con bacteriuria asintomática, que desapareció con tratamiento antibiótico adecuado (23). Las cifras de depuración de creatinina también están disminuidas en $58 \%$ de las pacientes con bacteriuria renal.

En pacientes con pielonefritis, Gilstrap y col. demostraron elevaciones del nitrógeno ureico (BUN) y de la creatinina sérica en el $20 \%$ de las pacientes y $40 \%$ de ellas tenían depuraciones de creatinina menores de $100 \mathrm{ml}$ por minuto. Van Dorsten y col. encontraron cifras extremadamente elevadas de creatinina sérica de más de $8 \mathrm{mg}$ por $\mathrm{dl}$ en $18 \%$ de embarazadas con pielonefritis.

Aunque parece que la pielonefritis aguda del embarazo no es el factor inicial de una nefropatía crónica, sí es un punto dentro de una secuencia, más fácil de detectar durante el embarazo, dadas las alteraciones de este a través de estudios prenatales urinarios sistémicos. La vigilancia a largo plazo de estas pacientes puede ser indispensable para el diagnóstico y tal vez la prevención o tratamiento de procesos continuos. Kincaid-Smith y Bullen encontraron que son beneficiosas las valoraciones radiográficas post-parto en casi $50 \%$ de las pacientes con pielonefritis durante el embarazo, ya que mostraron anomalías urográficas como estenosis uretral o cálculo. Hernández y col. encontraron una mayor incidencia de nefrosis y necrosis papilar después de períodos de pielonefritis aguda. Por lo tanto, las urografías post-parto en pacientes con pielonefritis aguda o bacteriuria recidivantes durante el embarazo identificarán causas potencialmente tratables de futuros trastornos renales.

c.Alteraciones hematológicas: Las anormalidades hematológicas que pueden ser consecuencia de la pielonefritis aguda incluyen leucocitosis con predominio de granulocitos, anemia, trombocitopenia e incremento de los productos de degradación de la fibrina. La anemia de la pielonefritis depende de la combinación de una mayor destrucción eritrocítica, como puede valorarse por las técnicas de marcar los eritrocitos con cromo, junto con una disminución de la producción eritrocítica que se manifiesta por la reticulocitopenia persistente y que se debe tal vez a la endotoxina. La trombocitopenia es un signo ominoso en mujeres con pielonefritis aguda y se ha encontrado en el $65 \%$ de sepsis y es signo de mal pronóstico (23).

d.Insuficiencia respiratoria del adulto: Se ha descrito también un cuadro respiratorio que acompaña a la pielonefritis que va desde tos mínima con infiltrados pulmonares de poca monta, hasta el síndrome de insuficiencia respiratoria del adulto, que obliga a recurrir a ventilación mecánica, presión telerrespiratoria positiva y concentraciones altas de oxígeno inspirado, para que sobreviva el enfermo. La lesión pulmonar surge cuando penetran en la circulación bacterias intactas o restos de la pared bacteriana en formas muertas. La complicación fue señalada por Cunningham y col. en 1984 en 4 pacientes de 250 embarazadas con infección urinaria y como factor coadyuvante en un caso de Elkington (24) en 1986 , en pacientes en segundo y tercer trimestre de gestación. La evolución reportada fue de 10 días y en dos casos se presentó parto pretérmino. El germen aislado fue E. coli en 3 casos y Klebsiella pneumoniae en 2 casos.

El cuadro clínico corresponde al de pielonefritis con fiebre alta, escalofríos, dolor en flanco, náuseas y vómito. En la mayoría de los casos la sintomatología respiratoria se inició entre 18 y 38 horas de tratamiento con disnea, tos y taquipnea. La frecuencia del pulso y la temperatura se elevan; la radiografía del tórax infiltrado y derrame uni o bilateralmente de grado variable. Los gases arteriales pueden mostrar hipoxemia, hipocarbia y alcalosis respiratoria. Las pruebas de laboratorio pueden mostrar compromiso de otros sistemas (anemia, trombocitopenia, creatinina y transaminasas altas). El manejo requiere una monitoría estricta cardiovascular, soporte ventilatorio y antibioterapia.

e.Shock séptico: Se calcula que el choque séptico complica el $25 \%$ de las 330.000 bacteremias por gram negativos de que se informa anualmente en los EE.UU. Es relativamente raro que ocurra este problema en pacientes menores de 40 años excepto embarazadas, recién nacidos y personas con alteración de sus mecanismos inmunológicos de defensa. El choque séptico durante el embarazo puede causar la evolución perinatal catastrófica y constituye un reto terapéutico importante para los médicos. El choque séptico es una complicación potencialmente letal de la infección bacteriana y puede ocurrir en las infecciones del tracto urinario en la mujer embarazada. El organismo responsable es con frecuencia una bacteria gram negativa que al sufrir disrupción de su pared, libera endotoxinas en el torrente sanguíneo afectando múltiples órganos, alterando su riego sanguíneo, alterando el complemento y produciendo coagulación intravascular. Estas endotoxinas son lipopolisacáridos y su fracción lípida es un componente activo de su toxicidad que produce alteraciones en varios sistemas.

- Cardiovasculares: Hipotensión, gasto cardíaco disminuido, aumento en la resistencia periférica, disminución de la contractibilidad cardíaca.

- Renales: Disminución del flujo sanguíneo y necrosis tubular aguda.

- Pulmonares: Organo blanco más importante. Congestión vascular, edema del tabique alveolar, infiltración leucocitaria, colapso alveolar difuso, aumento de la resistencia vascular, hipoxemia, hiperventilación y alcalosis respiratoria.

- Hematológicos: Anemia, consumo de factores de coagulación, coagulación intravascular diseminada.

Parker y Parrillo (25) resumieron un complejo teórico que describe la patogenia del choque séptico humano (Tabla 5). Una variedad de microorganismos incitadores (endotoxina, exotoxina, viremia) son capaces de iniciar la formación de mediadores vasoactivos e inflamatorios. La activación 
Tabla 5

FISIOPATOLOGIA DEL SHOCK SEPTICO

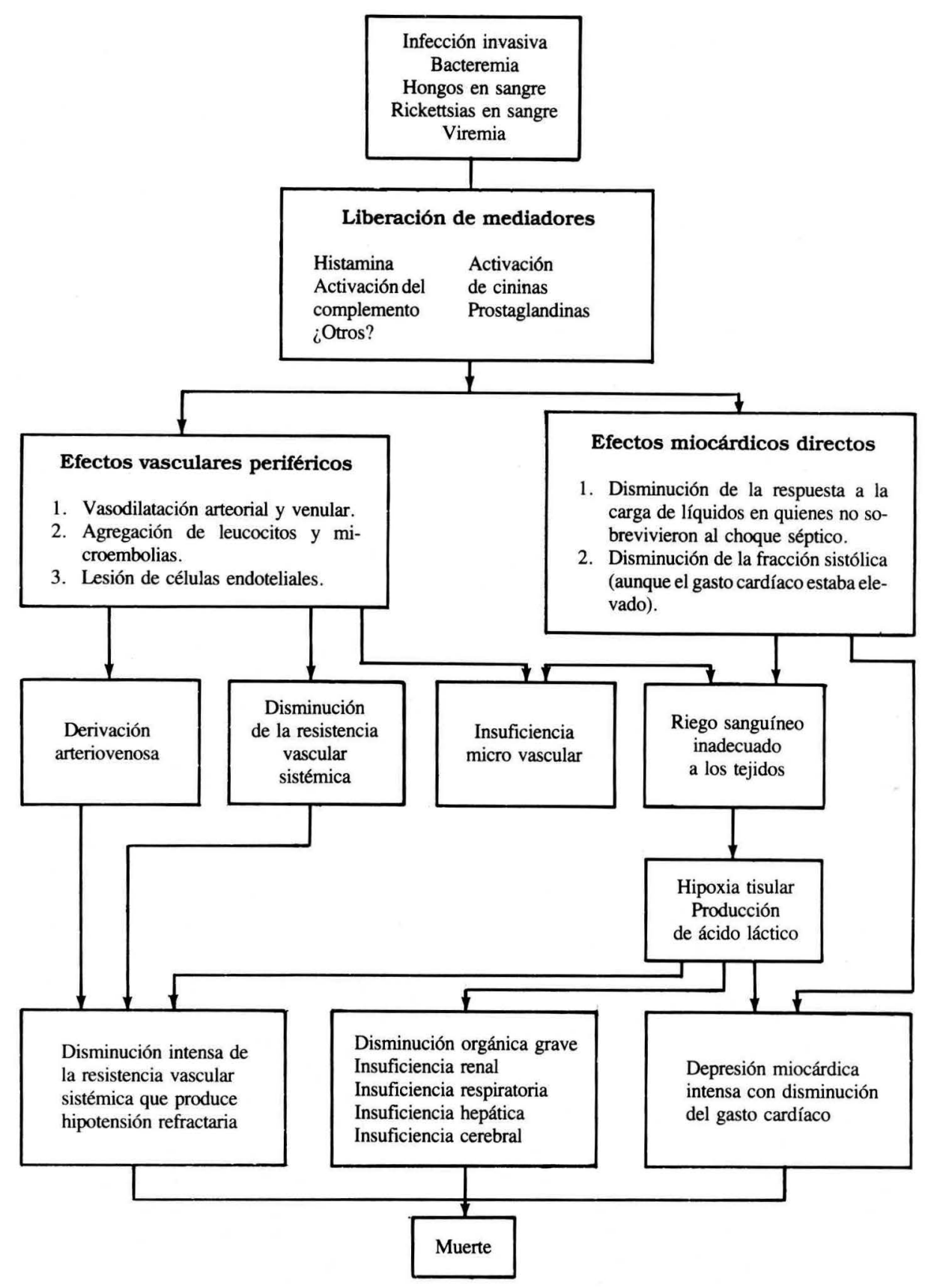

del sistema de complemento, la fibrinolisis y la secreción de sustancias vasoactivas (bradicinina, histamina, prostaglandinas) produce dilatación periférica, microembolias regionales y lesión de células endoteliales. La insuficiencia microvascular de estos cambios, combinada con un flujo sanguíneo regional inadecuado, produce la disfunción multiorgánica grave que afecta pulmones, riñones, corazón y sistema nervioso central. Ocurre hipotensión refractaria si el gasto cardíaco ventricular izquierdo normal o aumentado no es suficiente para compensar la resistencia vascular periférica. Esto se complica con la depresión de la función miocárdica. Es posible que en las etapas tempranas del cho- que séptico haya una baja resistencia vascular periférica con gasto elevado y disminución relativa del volumen intravascular. El choque tardío involucra después la superimposición de factor depresivo miocárdico endógeno vascular sistémico en ausencia de agentes presores. En consecuencia, la hipoxia tisular y la acidemia láctica dificultan a las células individuales la utilización del oxígeno con graves consecuencias materno fetales.

En cuanto al manejo del choque séptico se debe elaborar un plan terapéutico que incluya: cuidados de sostén, tratamiento de volumen, vigilancia hemodinámica con penetración corporal, agentes inotrópicos y vasopresores (Tabla 6). 




Cunnigham reporta tres casos de choque endotóxico en 99 pacientes embarazadas con pielonefritis. Adams (26) reporta 8 casos en una revisión de 4 años, en pacientes en segundo y tercer trimestre del embarazo, con una muerte materna y una fetal. Describe dos de sus casos que presentan al ingreso un cuadro de infección renal severa y que en un período corto desencadenan en un cuadro de shock. En ambos casos se aisló E. coli de la orina.

\section{B. Obstétricas:}

Prematurez: Aunque los datos sobre bacteriuria y parto pretérmino son ambiguos, está bien demostrada la relación entre la pielonefritis y trabajo de parto pretérmino. Antes del empleo sistémico de urocultivo y tratamiento de embarazadas con infección, solía haber una incidencia de 20 a $50 \%$ de trabajo de parto pretérmino en mujeres con pielonefritis. En fecha reciente, Leveno y col. encontraron una tasa de $15 \%$ de recién nacidos pretérminos con menos de 2.500 grs de peso en mujeres con pielonefritis, comparadas con una incidencia del $10 \%$ en aquellas sin pielonefritis.

El diagnóstico temprano y el pronto inicio del tratamiento adecuado es indispensable en pacientes con pielonefritis. $\mathrm{Si}$ se retrasa el diagnóstico o tratamiento, puede iniciarse un trabajo de parto pretérmino que aumenta la morbilidad y
Si no hay mejoría se añade:
2) Dobutamina
3) Isoproterenol

Se inicia con fenilefrina

Si la SVRI no mejora, se añade noradrenalina

mortalidad perinatales.

Hay dos hipótesis sobre el inicio de trabajo de parto pretérmino en la pielonefritis (27):

La primera hipótesis señala que una endotoxina puede estimular la contractibilidad miometral por vía de las prostaglandinas. La segunda hipótesis es que una infección bacteriana y las endotoxinas tienen efecto destructivo sobre los vasos del útero y placenta. En placentas humanas Naeye encontró una mayor incidencia de retraso del crecimiento placentario en pacientes cuyos embarazos habían estado complicados con UTI.

Gruneberg y col. encontraron una elevada tasa de prematurez y disminución del peso al nacer en hijos de mujeres bactoriúricas refractarias a tratamiento o recidivas.

Investigadores previos habían encontrado que las pacientes bacteriúricas que no respondían al tratamiento tenían mayores posibilidades de afección renal subclínica. Por ello es probable que el diagnóstico equivocado de pielonefritis temprana y el tratamiento inadecuado subsiguiente produzca mala evolución fetal, por lo que se debe tener en mente una conducta agresiva en todas las embarazadas con sospecha de infección que permita evolución satisfactoria con el tratamiento. 


\section{BIBLIOGRAFIA}

1. Glynn AA, Brumfitt W, Howard CJ. K antigens of Escherichia coli and renal involvement in urinary tract. Lancet 1971; 1: 514.

2. Gary DV, Hankins $P$, Whalley. J. Infecciones agudas de vías urinarias durante el embarazo. Clin Obstet y Ginecol 1985; (2): 329.

3. Mabeck CE, Orskov I. Escherichia coli serotypes and renal involvement in urinary tract infection. Lancet $1971 ; 1: 1312$.

4. Stamey TA, Sexton CC. The role of vaginal colonization with enterobacteriaceae in recurrent urinary infections. J Urol 1977; 133: 214.

5. Schaeffer AJ, Jones JM, Dunn JK. Association of in vitro Escherichia coli adherence to vaginal and bucal ephitelial cells with susceptibility of women to recurrent urinary tract infection. N Engl J Med 1981; 304: 1062.

6. Davinson JM. Fisiología de las vías urinarias durante el embarazo. Clin Obstet y Ginecol 1985; 2: 317.

7. Fowler JE Jr., STAMEY TA. Studies of introital colonization in women with recurrent urinary infections. VII. The role of bacterial adherence. J Urol 1977; 117: 472.

8. Harber MJ, Chick S, Mackensie R et al. Lack of adherence to ephitelial cells by freshly isolated urinary pathogens. Lancet 1982; 1(8272): 586

9. Harris RE. The significance of eradication of bacteriuria during pregnancy. Obstet Gynecol 1979; 53: 71.

10. Shari Thomas, Narender N. Bhatia. Nuevos métodos para el tratamiento de las infecciones urinarias. Clin de Ginecol y Obstet 1989; 4: 897.

11. Linda M., Dairiki Shortliffe, Thomas A. Stamey. Infecciones urinarias en mujeres adultas. Urología de Campel 1988; 861.

12. Harris RE, Dunnihoo DR. The incidence and significance of urinary calculi in pregnancy. Am J Obstet Gynecol 1967; 99: 237.

13. Horowitz E, Schmith JD. Cálculos renales durante el embarazo. Clin Obstet y Ginecol 1985; 2: 407.
14. Laverson PL, Hankins GDV, Quirk JG. Ureteral obstruction during pregnancy. J Urol 1984; 131: 327.

15. Barret II RJ, Peters III WA. Pregnancy following urinary distension. Obstet Gynecol 1983; 62: 582.

16. Kunnin CM, Zacha E, Paquin AJ. Urinary tract infections in school children I. Prevalence of bacteriuria and asociated urologic findings. $\mathrm{N}$ Engl J Med 1962; 26: 1287.

17. Lomanto MA, Sánchez J, Lomanto A. Bacteriuria asintomática en el embarazo. Rev Col Obstet y Ginecol.

18. Harris RE, Gilstrap LC. Cystitis during pregnancy; a distinct clinical entity. Obstet Gynecol 1981; 198: 578.

19. Mark G Martens. Pielonefritis. Clin Ginecol y Obstet 1989; 2: 293.

20. Duff P. Pyelonephritis in pregnancy. Clin Obstet y Gynecol 1984; 27: 17.

21. Robert E Harris. Infecciones agudas del tracto urinario y problemas posteriores. Clin Obstet y Ginecol 1984; 4: 1109.

22. Hibbard I, Thrupp L, Summeril S, Samle M, Adams R. Treatment of pyelonephritis in pregnancy. Am J Obstet Gynecol 1967; 98: 609.

23. Gilstrap LC, Cunningham FG, Whalley PJ. Acute pyelonephritis in pregnancy: an anterospective study. Obstet Gynecol 1981; 57: 409.

24. Elkington $\mathrm{KW}$, Greb LC. Adult respiratory distress syndrome as a complication of acute pyelonephritis during pregnancy: case report and discussion. Obstet Gynecol 1986; 67: 185.

25. Parker MM, Parrillo JE. Septic shock. Hemodynamics and pathogenesis. JAMA 1983; 250: 3324.

26. Adams RH, Pritchard JA. Bacterial shock in obstetrics and ginecology. Obstet Gynecol 1960; 16: 387.

27. Weslwy Lee, David B. Cotton y col. Tratamiento del choque séptico durante el embarazo. Clin Ginecol y Obstet 1989; 2: 419. 